\title{
Modeling and multi-objective optimization of surface roughness and productivity in dry turning of AISI 52100 steel using (TiCN-TiN) coating cermet tools
}

\author{
Ouahid Keblouti $^{a^{*}}$, Lakhdar Boulanouar ${ }^{\mathrm{a}}$, Mohamed Walid Azizi ${ }^{\mathrm{a}}$ and Mohamed Athmane Yallese ${ }^{\mathrm{b}}$
}

${ }^{a}$ Advanced Technologies in Mechanical Production Research Laboratory (LRTAPM), Annaba University, Algeria

${ }^{b}$ Mechanics and Structures Research Laboratory (LMS), Guelma University, Algeria

CHRONICLE ABSTRACT

Article history:

Received April 42016

Received in Revised Format

June 162016

Accepted July 82016

Available online

July 122016

Keywords:

Machining processes

Surface roughness

Cutting force

Modeling

Coating tools

ANOVA

RSM

\begin{abstract}
The present work concerns an experimental study of turning with coated cermet tools with TiCNTiN coating layer of AISI 52100 bearing steel. The main objectives are firstly focused on the effect of cutting parameters and coating material on the performances of cutting tools. Secondly, to perform a Multi-objective optimization for minimizing surface roughness ( $\mathrm{Ra}$ ) and maximizing material removal rate by desirability approach. A mathematical model was developed based on the Response Surface Methodology (RSM). ANOVA method was used to quantify the cutting parameters effects on the machining surface quality and the material removal rate. The results analysis shows that the feed rate has the most effect on the surface quality. The effect of coating layers on the surface quality is also studied. It is observed that a lower surface roughness is obtained when using PVD (TiCN-TiN) coated insert when compared with uncoated tool. The values of root mean square deviation and coefficient of correlation between the theoretical and experimental data are also given in this work where the maximum calculated error is $2.65 \%$.
\end{abstract}

\begin{tabular}{cccc}
\hline & & Nomenclature & \\
\hline$V$ & cutting speed $(\mathrm{m} / \mathrm{min})$ & $D F$ & degrees of freedom \\
$f$ & feed rate $(\mathrm{mm} / \mathrm{rev})$ & $S S$ & sum of squares \\
$d$ & depth of cut $(\mathrm{mm})$ & $M S$ & mean squares \\
$F_{a}$ & feed force $(\mathrm{N})$ & $P C$ & Percentage contribution ratio $(\%)$ \\
$F_{r}$ & thrust force $(\mathrm{N})$ & $R^{2}$ & determination coefficient \\
$F_{t}$ & tangential cutting force $(\mathrm{N})$ & $\alpha$ & clearance angle $\left(^{\circ}\right)$ \\
$R a$ & arithmetic average of absolute roughness $(\mu \mathrm{m})$ & $\chi_{r}$ & cutting edge angle $\left(^{\circ}\right)$ \\
$X_{i}$ & coded machining parameters & $\gamma$ & rake angle $\left(^{\circ}\right)$ \\
$a_{j}$ & coefficients of linear terms & $\lambda$ & cutting edge inclination angle $\left(^{\circ}\right)$ \\
$a_{i i}$ & quadratic terms & $p$ & tested parameters \\
$a_{i j}$ & cross-product terms & $j$ & level number of tested parameters \\
$B U E$ & built-up-edge & $r$ & repetition of tested parameters \\
$A N O V A$ & analysis of variance & $r$ & correlation coefficient \\
$R M S$ & response surface method & $e$ root mean square of percentage deviation \\
\hline
\end{tabular}

* Corresponding author. Tel. : +213-799983969 


\section{Introduction}

Coated cemented carbide cutting tools are extensively used in Material cutting. Several research works were investigated in order to improve the performance of these cutting tools with regards to the wear resistance, thermal shock resistance and surface quality of workpiece (Berkani et al. 2015; Tebassi et al. 2016). The coating material of cutting tools contributes efficiently in improving the cutting conditions, where, its effects on the performance of cutting tools was studied in prior investigations Grzesik and Nieslony (2004). It protects the wear substrate, improves the crack resistance and created a thermal barrier (Das et al. (2015). Among coating layers used there are the titanium carbide (TiC), titanium nitride (TiN), titanium carbonitride (TiCN), titanium aluminum nitride (TiAlN), and aluminum oxide $\left(\mathrm{Al}_{2} \mathrm{O}_{3}\right)$ are the most selected materials Sahoo and Sahoo (2012). These layers are mostly deposited with Chemical Vapor Deposition (CVD) or by Physical Vapor Deposition (PVD) technique Aurich et al. (2012). The investigations conducted by Grzesik (1998) highlights the crucial effect of different types of coating at dry machining of carbon-based steel AISI 1045 and AISI 304 stainless steel. He used three type of coating layers: $\mathrm{TiC}, \mathrm{TiC} / \mathrm{TiN}$, and $\mathrm{TiC} / \mathrm{Al}_{2} \mathrm{O}_{3} / \mathrm{TiN}$. He found that the contact area tool-chip, of the couple tool-material $\mathrm{TiC} / \mathrm{Al}_{2} \mathrm{O}_{3} / \mathrm{TiN}$-AISI 1045 gives lower values of friction factor and the contact pressure compared to the couple TiC/TiN-AISI 1045 and TiC-AISI 1045. The tribological phenomenon at tool-chip interface was investigated by Zhang et al. (2015) in dry cutting of hardened steel AISI 1045 using two types of coated cemented carbide. The first one is a nano-scale surface textured on the rake face of the cutting tool followed by the deposition of Ti55Al45N hard-coatings. In the second insert, the order sequence of coating layers was inverted. A significant decrease in cutting forces; cutting temperature and friction coefficient at the tool-chip interface were found. Where, the textured tool reduces the contact area and then the friction at the tool-chip interface. Sahoo and Sahoo (2013) conducted an experimental investigation on the flank wear behavior in hard turning using multilayer coated carbide ( $\left.\mathrm{TiN} / \mathrm{TiCN} / \mathrm{Al}_{2} \mathrm{O}_{3} / \mathrm{TiN}\right)$ insert. They found that the flank wear value increases with increasing cutting speed, feed rate and depth of cut. They also observed that both abrasion and diffusion wear mechanisms are predominantly at extreme cutting conditions. A comparative study has been found by Cakir et al. (2009) using PVD coated (TiAlN) insert and CVD coated ( $\mathrm{TiCN} / \mathrm{Al}_{2} \mathrm{O}_{3} / \mathrm{TiN}$ ) insert. They observed that the lower surface roughness a value is obtained by employing coated (TiAlN) insert.

In machining process, the Designs and method such as factorial designs, response surface methodology (RSM) and Taguchi method are frequently used for analyzing experimental data, which allowed to reduce the consuming time and cost. In order to study the performance of coated carbide inserts, ceramic and cubic boron nitride (CBN) tools, recently a various investigation have been carried out. Azizi et al. (2012) conducted an experimental investigation to determine the significant parameters affecting the surface roughness and cutting forces, in finish hard turning of AISI 52100 steel, by using the response surface methodology (RSM). They applied an optimization study of machining conditions to produce the lowest surface roughness with minimal cutting force components using desirability function approach for multiple response factors optimization. They concluded that the feed rate, workpiece hardness and cutting speed have significant effects in reducing the surface roughness; whereas the depth of cut, workpiece hardness and feed rate are observed to have a statistically significant impact on the cutting force components than the cutting speed. Chinchanikar and Choudhury (2013) investigated the effect of work materials hardness and cutting parameters on cutting forces, surface roughness and tool life, when turning hardened AISI 4340 steel at two levels of hardness ( 35 and 45 HRC), using coated tungsten based cemented carbide inserts. Mathematical models were developed for surface roughness and cutting force components using the response surface methodology (RSM). The results concluded that the Cutting forces get affected mainly by depth of cut followed by feed; Surface roughness gets affected significantly at higher feed and depth of cut Cutting speed followed by depth of cut was found to be the most influencing factors on tool life, especially when turning harder work piece. Hessainia et al. (2013) Developed mathematical prediction model of the surface roughness for turning operations of $42 \mathrm{CrMo} 4$ hardened steel by $\mathrm{Al} 2 \mathrm{O} 3 / \mathrm{TiC}$ mixed ceramic cutting insert, based on cutting parameters and tool vibration in radial and in main cutting force directions. They reported according to their experimental 
results that the feed rate is the dominant factor affecting the tow criteria of surface roughness (Ra and $\mathrm{Rt}$ ), whereas vibrations in two directions have a low effect on the surface roughness. Elbah et al. (2013) had compared between the surface roughness criteria ( $\mathrm{Ra}, \mathrm{Rz}$ and $\mathrm{Rt}$ ) of the wiper inserts with conventional inserts during hard turning of AISI 4140 hardened steel $(60 \mathrm{HRC})$, The analysis of results reveals that the feed rate and depth of cut have significant effects in reducing the surface roughness. Asiltürk and Akkus (2011) conducted an optimization study by machining a hardened AISI 4140 (51HRC) steel with coated carbide cutting tools using the Taguchi method to obtain optimum cutting parameters. They applied the statistical methods of signal to noise ratio (SNR) and the analysis of variance (ANOVA) to investigate effects of cutting speed, feed rate and depth of cut on surface roughness. They reported that the feed rate has the most significant effect on $\mathrm{Ra}$ and $\mathrm{Rz}$, In addition, the effects of two factor interactions of the feed rate-cutting speed and depth of cut-cutting speed appear to be important

In this work, an experimental investigation was found in order to study the effect of cutting parameters (namely the cutting speed (Vc), fed rate (f) and the depth of cut (d)) on surface roughness and material removal rate and to perform a Multi-objective optimization intended for minimize roughness $\mathrm{Ra}$ and maximize material removal rate by desirability approach. A comparison was performed between uncoated and coated cemented carbide tools with $(\mathrm{TiCN} / \mathrm{TiN})$ coating layer. The insets have identical substrate composition and geometry. The effect of tool wear was neglected by using for each experiment a fresh cutting edge. In addition, a mathematical model was developed based on the Response Surface Methodology (RSM). ANOVA method was used to quantify the cutting parameters effects on the machining surface quality and the material removal rate. The analysis shows that among the studied cutting parameters, the feed rate has the most important effect on the surface quality with a contribution rate above $85 \%$. The effect of coating layers on the surface quality is also studied. It is observed that a lower surface roughness value is achieved using PVD (TiCN/TiN) coated insert when compared to the uncoated tool.

\section{Experimental setup and design}

\subsection{Experimental design}

This work is an experimental study focused on the effect of cutting parameters on surface roughness, and material removal rate with, developing a correlation between them. The experimental design involves variation of three factors at three levels (low, medium and high), including cutting speed (v), feed rate (f) and depth of cut (d) as indicated in Table 1. The selected experimental design requires 27 runs with 26 degrees of freedom (DF). For each run, one test was performed (no replications). Also a random order was determined for running the tests.

Table 1

Operating conditions of cutting parameters

\begin{tabular}{lccc}
\hline Level & Cutting speed, $\mathrm{v}(\mathrm{m} / \mathrm{min})$ & Feed rate, $\mathrm{f}(\mathrm{mm} / \mathrm{rev})$ & Cutting depth, $\mathrm{d}(\mathrm{mm})$ \\
\hline Low & 150 & 0.08 & 0.15 \\
Medium & 200 & 0.12 & 0.30 \\
High & 250 & 0.16 & 0.45 \\
\hline
\end{tabular}

The analysis of variance (ANOVA) method was used to quantify the impact of the cutting speed (v), feed rate (f) and depth of cut (d) and their interactions on the surface roughness. The obtained results were analyzed using Design-Expert ${ }^{\circledR}$ Software, statistical analysis software, which is widely used in engineering optimizations. In addition, the response surfaces methodology (RSM) was used in order to determine the relationship between the independent process parameters with the desired response and exploring the effect of these parameters on responses, including six steps Myers \& Montgomery, (2002). 
These are, in the following order, (1) define the independent input variables and the desired responses with the design constants, (2) adopt an experimental design plan, (3) perform regression analysis with the quadratic model of RSM, (4) calculate the statistical analysis of variance (ANOVA) for the independent input variables in order to find which parameter significantly affects the desired response, then, (5) determine the situation of the quadratic model of RSM and decide whether the model of RSM needs screening variables or not and finally, (6) Optimize and conduct confirmation experiment and verify the predicted performance characteristics. In the present work, the RSM-based second order mathematical model is given by the following Eq. (1):

$$
Y=a_{0}+\sum_{i=1}^{n} a_{i i} X_{i}+\sum_{i=1}^{n} a_{i i} X_{i}^{2}+\sum_{i \neq j}^{n} a_{i j} X_{i} X_{j}
$$

Where, $\mathrm{Y}$ : is the estimated response (surface roughness or cutting forces). $\mathrm{a}_{0}, \mathrm{a}_{\mathrm{i}}, \mathrm{a}_{\mathrm{ij}}$ and $\mathrm{a}_{\mathrm{ii}}$ are the adopted mathematical model coefficients. They are not identified and must be calculated from the experimental results. $\mathrm{x}_{\mathrm{i}}$, are variables or factors influences the response $(\mathrm{Y})$, corresponding to the studied cutting condition parameters such as cutting speed (V), feed rate (f) and depth of cut (d) and their interactions.

\subsection{Work piece material and Cutting inserts}

The aim of this experimental work is to study the effect of cutting parameters on surface roughness and material removal rate and to develop a correlation between them. In this study a turning runs are carried out in dry conditions using a universal lathe SN 40C type with $6.6 \mathrm{~kW}$ spindle power. The work piece material is AISI 52100 steel in the form of round bars with $66 \mathrm{~mm}$ of diameter and $380 \mathrm{~mm}$ cutting length. This material is widely used in manufacturing of automotive components regarding to their properties like high tensile strength, shock resistance and Brinell hardness about $230 \mathrm{HB}$. The chemical composition of AISI 52100 steel is given in Table 1. Coating effect on the cutting performances is investigated using two type of cutting inserts. The first type is GC 1525 coated insert (PVD with $\mathrm{TiCN} / \mathrm{TiN}$ ) layer sequence, which is an ISO class P15 grade, with a total thickness of $3 \mu \mathrm{m}$. The main coating layer includes titanium carbonitride $(\mathrm{TiCN})$ and a thin layer of titanium nitride (TiN). The second insert is CT5015 uncoated cermet. The two insets (GC 1525 and CT5015) have an identical substrate with the same geometry designation as CNMG 120408. For each experiment a fresh cutting edge was used. A right hand style tool holder designated by ISO as CSBNR2525M12 was used for mounting the inserts. It is characterized by the following angles: $\chi r=75^{\circ}, \lambda=-6^{\circ}, \gamma=-6^{\circ}, \alpha=+6^{\circ}$. The measurement of the arithmetic surface roughness $(\mathrm{Ra})$ is obtained from a Surftest 201 Mitutoyo roughness-meter, as showing in experimental design flowchart Fig.1. The machined length is $24 \mathrm{~mm}$ with a basic span of 3 $\mathrm{mm}$. The measurements were repeated at three equally spaced locations around the circumference of the workpiece at $120^{\circ}$ and the result is an average of these values. The surface roughness is directly measured on the workpiece, without dismounting from the lathe, in order to reduce error measurements. Finally, the material removal rate (MRR) is calculated using Eq. (2)

$$
\mathrm{MRR}=\mathrm{V}^{*} \mathrm{f}^{*} \mathrm{~d}(\mathrm{~cm} 3 / \mathrm{min})
$$

Table 2

Chemical composition of AISI 52100 steel

\begin{tabular}{llllllll}
\hline $\mathrm{C}$ & $\mathrm{Si}$ & $\mathrm{Mn}$ & $\mathrm{Cr}$ & $\mathrm{Ni}$ & $\mathrm{Mo}$ & $\mathrm{V}$ & $\mathrm{Cu}$ \\
\hline 1.09 & 0.256 & 0.35 & 1.382 & 0.077 & 0.017 & 0.005 & 0.150 \\
\hline
\end{tabular}

\section{Analysis and discussion of experimental results}

In this work a comparative assessment of coated and uncoated cutting tool was made in order to quantify the impact of selected turning parameters on surface roughness (Ra) and material removal rate (MRR), their experimental results are showing in Table 3. 


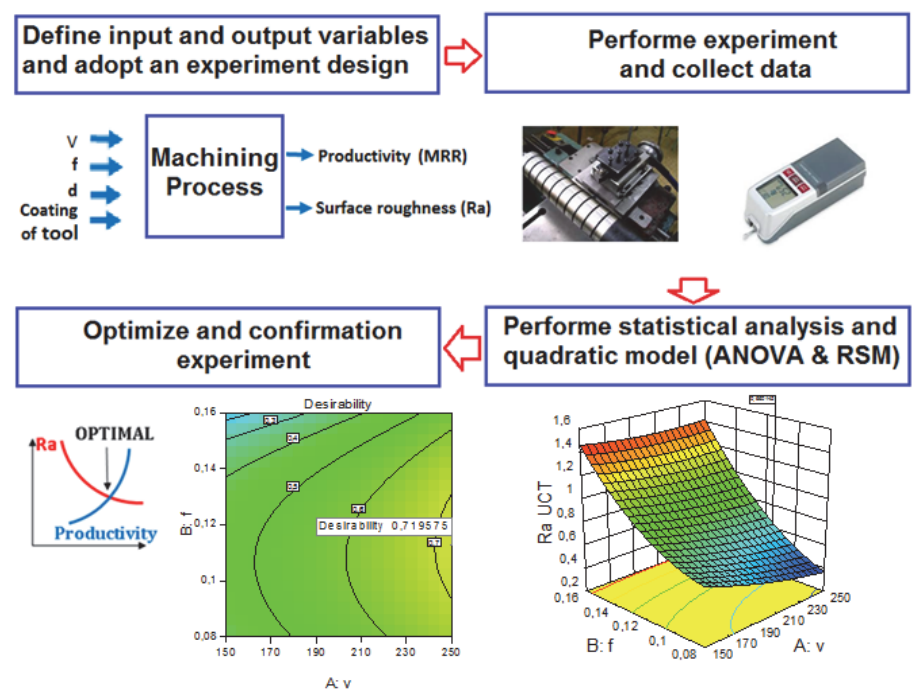

Fig.1. Experimental design flowchart

Table 3

Experimental results for surface roughness and material removal rate

\begin{tabular}{|c|c|c|c|c|c|}
\hline \multicolumn{3}{|c|}{ machining parameters } & \multirow{2}{*}{$\begin{array}{c}\text { Coated inserts } \\
\mathrm{Ra}(\mu \mathrm{m})\end{array}$} & \multirow{2}{*}{$\begin{array}{c}\text { Uncoated inserts } \\
\mathrm{Ra}(\mu \mathrm{m})\end{array}$} & \multirow{2}{*}{$\begin{array}{c}\text { Material Removal Rate } \\
\mathrm{Q}\left(\mathrm{cm}^{3} / \mathrm{min}\right)\end{array}$} \\
\hline $\mathrm{V}(\mathrm{m} / \mathrm{min})$ & $\mathrm{f}(\mathrm{mm} / \mathrm{rev})$ & $\mathrm{d}(\mathrm{mm})$ & & & \\
\hline 150 & 0,08 & 0,15 & 0,47 & 0,96 & 1,8 \\
\hline 150 & 0,08 & 0,3 & 0,45 & 0,8 & 3,6 \\
\hline 150 & 0,08 & 0,45 & 0,51 & 0,6 & 5,4 \\
\hline 150 & 0,12 & 0,15 & 0,78 & 0,77 & 2,7 \\
\hline 150 & 0,12 & 0,3 & 0,89 & 0,9 & 5,4 \\
\hline 150 & 0,12 & 0,45 & 0,84 & 0,96 & 8,1 \\
\hline 150 & 0,16 & 0,15 & 1,15 & 1,39 & 3,6 \\
\hline 150 & 0,16 & 0,3 & 1,18 & 1,45 & 7,2 \\
\hline 150 & 0,16 & 0,45 & 1,42 & 1,46 & 10,8 \\
\hline 200 & 0,08 & 0,15 & 0,52 & 0,4 & 2,4 \\
\hline 200 & 0,08 & 0,3 & 0,4 & 0,42 & 4,8 \\
\hline 200 & 0,08 & 0,45 & 0,51 & 0,47 & 7,2 \\
\hline 200 & 0,12 & 0,15 & 0,7 & 0,72 & 3,6 \\
\hline 200 & 0,12 & 0,3 & 0,82 & 0,74 & 7,2 \\
\hline 200 & 0,12 & 0,45 & 0,7 & 0,93 & 10,8 \\
\hline 200 & 0,16 & 0,15 & 1,06 & 1,37 & 4,8 \\
\hline 200 & 0,16 & 0,3 & 1,06 & 1,37 & 9,6 \\
\hline 200 & 0,16 & 0,45 & 1,3 & 1,44 & 14,4 \\
\hline 250 & 0,08 & 0,15 & 0,49 & 0,32 & 3 \\
\hline 250 & 0,08 & 0,3 & 0,39 & 0,37 & 6 \\
\hline 250 & 0,08 & 0,45 & 0,5 & 0,37 & 9 \\
\hline 250 & 0,12 & 0,15 & 0,46 & 0,57 & 4,5 \\
\hline 250 & 0,12 & 0,3 & 0,75 & 0,72 & 9 \\
\hline 250 & 0,12 & 0,45 & 0,58 & 0,83 & 13,5 \\
\hline 250 & 0,16 & 0,15 & 1,02 & 1,26 & 6 \\
\hline 250 & 0,16 & 0,3 & 0,9 & 1,27 & 12 \\
\hline 250 & 0,16 & 0,45 & 1,15 & 1,3 & 18 \\
\hline
\end{tabular}

\subsection{ANOVA results and effects of machining parameters}

The results of variance analysis for surface roughness criteria $(\mathrm{Ra})$ of coated and uncoated cermet inserts are given in Tables 4 and 5. These tables also show the degrees of freedom (DF), sum of squares (SSp), p-values and the percentage of contribution (PC) (Lin, 2002; Aouici et al. 2016). The p-value is used to determine the significance of each factor if its value is lower than 0.05 . The characterization of the machined surface quality was limited to the criteria of arithmetic mean roughness (Ra). From Table 4 It can be concluded that the feed rate is the most important parameter affecting surface finish compared to 
the other factors and there interaction and its contribution is $93.97 \%$ and $82.09 \%$ for coated and uncoated inserts respectively. The second factor affecting the surface quality is the cutting speed which contributes by $2.32 \%$ and $7.41 \%$ for coated and uncoated inserts respectively. The cutting depth gives lower influences on the surface roughness where its contribution is less than $2 \%$. This results can be explained by the phenomenon of the grooving helicoidally furrows on the finish machining surface caused by the rising of feed rate combined with tool-workpiece movement as showing in another study Bouzid et al. (2014), Bouchelaghem et al. (2007), on the other hand, this phenomenon is explained by the reduces of feed rate caused low cutting forces, which resulting less vibration after that provide better surface finish. Similar investigations have been made in the same context, for example, yallese et al. (2009) and Hessainia et al. (2015), where they found that the improvement of surface roughness ( $\mathrm{Ra}$ ) is caused by decreasing in the cutting forces at high cutting speeds accordingly influences the machining system stability. Fig. 2 and Fig. 3 show the main effect of the studied factors on the surface roughness. It is clear that the surface roughness is proportional to the increase of the feed rate and cutting depth and inversely proportional to the cutting speed.

\section{Table 4}

Analysis of variance results of surface roughness Ra using Coated inserts

\begin{tabular}{lllllllll}
\hline Source & Sum of Squares & df & \multicolumn{1}{c}{ Mean Square } & F Value & p-value & Cont \% & Remarks \\
\hline Model & 4,26 & 9 & 0,47 & 212,47 & $<0,0001$ & 99,06 & significant \\
$A-v$ & 0,1 & 1 & 0,1 & 45,43 & $<0,0001$ & 2,327 & significant \\
$B-f$ & 4,04 & 1 & 4,04 & 1813,69 & $<0,0001$ & 93,954 & significant \\
$C-d$ & 0,055 & 1 & 0,055 & 24,6 & 0,0001 & 1,275 & significant \\
$A B$ & $8,33 E-04$ & 1 & $8,33 E-04$ & 0,37 & 0,549 & 0,019 & not significant \\
$A C$ & $2,08 E-04$ & 1 & $2,08 E-04$ & 0,093 & 0,7635 & 0,004 & not significant \\
$B C$ & $3,33 E-05$ & 1 & $3,33 E-05$ & 0,015 & 0,9041 & 0,007 & not significant \\
$A^{2}$ & $2,18 E-03$ & 1 & $2,18 E-03$ & 0,98 & 0,3362 & 0,057 & not significant \\
$B^{2}$ & 0,06 & 1 & 0,06 & 26,82 & $<0,0001$ & 1,395 & not significant \\
$C^{2}$ & $5,14 E-04$ & 1 & $5,14 E-04$ & 0,23 & 0,6371 & 0,011 & significant \\
\hline Residual & 0,038 & 17 & $2,23 E-03$ & - & - & 0,883 & & - \\
\hline Total & 4,3 & 26 & & - & - & - & - & - \\
\hline
\end{tabular}

Table 5

Analysis of variance results of surface roughness Ra using Uncoated inserts

\begin{tabular}{|c|c|c|c|c|c|c|c|}
\hline Source & Sum of Squares & df & Mean Square & F Value & p-value & Cont $\%$ & Remarks \\
\hline Model & 3,75 & 9 & 0,42 & 45,4 & $<0.0001$ & 95,90 & significant \\
\hline$A-v$ & 0,29 & 1 & 0,29 & 31,45 & $<0.0001$ & 7,416 & significant \\
\hline$B-f$ & 3,21 & 1 & 3,21 & 349,43 & $<0.0001$ & 82,09 & significant \\
\hline C-d & 0,02 & 1 & 0,02 & 2,18 & 0,1583 & 0,511 & not significant \\
\hline $\mathrm{AB}$ & 0,057 & 1 & 0,057 & 6,25 & 0,0229 & 1,457 & significant \\
\hline $\mathrm{AC}$ & 0,017 & 1 & 0,017 & 1,84 & 0,193 & 0,434 & not significant \\
\hline $\mathrm{BC}$ & 0,015 & 1 & 0,015 & 1,6 & 0,2229 & 0,383 & not significant \\
\hline $\mathrm{A} 2$ & $6,23 \mathrm{E}-03$ & 1 & $6,23 \mathrm{E}-03$ & 0,68 & 0,4216 & 0,159 & not significant \\
\hline B2 & 0,14 & 1 & 0,14 & 15,14 & 0,0012 & 3,580 & significant \\
\hline $\mathrm{C} 2$ & $2,96 \mathrm{E}-05$ & 1 & $2,96 \mathrm{E}-05$ & $3,23 \mathrm{E}-03$ & 0,9554 & 0,000 & not significant \\
\hline Residual & 0,16 & 17 & $9,18 \mathrm{E}-03$ & - & - & 4,092 & - \\
\hline Total & 3,91 & 26 & - & - & - & - & - \\
\hline
\end{tabular}
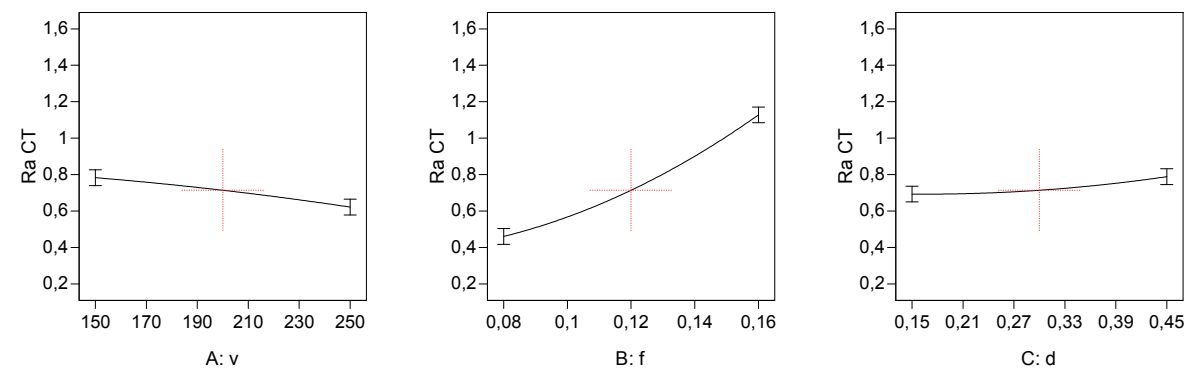

Fig. 2. Main effect of factor coated inserts 

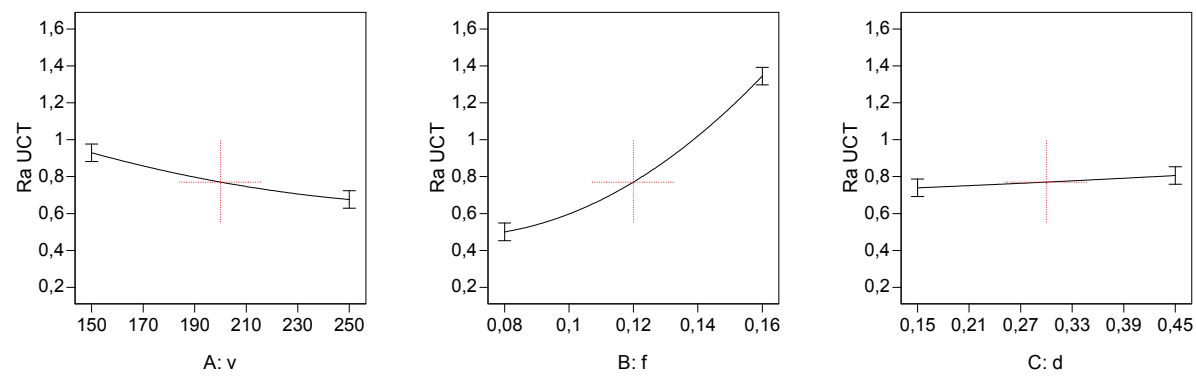

Fig. 3. Main effect of factor Uncoated inserts

\subsection{Regression equations}

The quadratic models for surface roughness $(\mathrm{Ra})$ were obtained from the experimental data. The values of the coefficients involved in Eq. (1) have been calculated by (RSM) using Design-Expert ${ }^{\circledR}$ Software. Mathematical equations of the fitted models for the arithmetic mean roughness (Ra) models of inserts with and without coating are given below in Eq. (3) and Eq.(4) respectively.

$$
\begin{aligned}
& R a_{\text {coated }}=0.178+0.004 \quad v-0.917 f-1.148 \quad d-4.667 e-006 \\
& +8.333 f . d+1.185 d^{2}
\end{aligned}
$$

\subsection{Adequacy test}

The adequacy of the obtained models is tested using (ANOVA) method, according to its results in Table 6 and Table 7. The quadratic models of surface roughness with and without coating insert, indicated that the relationship between the response variable and the predictors factors is significant within the confidence limit, which is illustrated by the $(p$-value $=0.000)$ at what time are less than alpha value (0.05). The coefficient of determination $\left(\mathrm{R}^{2}\right)$ was estimated to check the accuracy of the fit. For the surface roughness with and without coating, the $\left(\mathrm{R}^{2}\right)$ values are $98.65 \%$ and 94.39 , respectively. The predicted coefficient of determination $\left(\mathrm{R}^{2}\right.$ pred $)$ for surface roughness using quadratic model with coated and uncoated insert is $97.7 \%$ and $88.11 \%$ respectively. Where they in excellent agreement; which indicate the fitness of the developed regression models.

Table 6

Fit Summary of surface roughness Ra using Uncoated inserts

\begin{tabular}{lllll}
\hline Source & \multicolumn{1}{c}{ Sequential p-value } & \multicolumn{1}{c}{ Adjusted R-Squared } & Predicted R-Squared & Remarks \\
\hline Linear & $<0.0001$ & 0,8871 & 0,8571 & \\
Interaction & 0,1513 & 0,8997 & 0,8382 & \\
Quadratic & $\underline{0,0094}$ & $\underline{0,9439}$ & $\underline{0,8811}$ & $\underline{\text { Suggested }}$ \\
Cubic & 0,0028 & 0,9831 & 0,9456 & Aliased \\
\hline
\end{tabular}

Table 7

Fit Summary of surface roughness Ra using Coated inserts

\begin{tabular}{lcccc}
\hline Source & Sequential p-value & Adjusted R-Squared & Predicted R-Squared & Remarks \\
\hline Linear & $<0,0001$ & 0,9733 & 0,9685 & - \\
Interaction & 0,9746 & 0,9697 & 0,9591 & - \\
Quadratic & $\underline{0,0007}$ & $\underline{0,9865}$ & $\underline{0,977}$ & Suggested \\
Cubic & 0,0261 & 0,9939 & 0,9845 & Aliased \\
\hline
\end{tabular}


Likewise, a test of the normality may possibly be made by constructing the normal probability plot of the residuals. If the underlying error distribution is normal, this plot will be similar to a straight line this plot is illustrated in Fig.4. This can be indicated that the transformation of the surface roughness results provides a good analysis, and the proposed models are adequate.
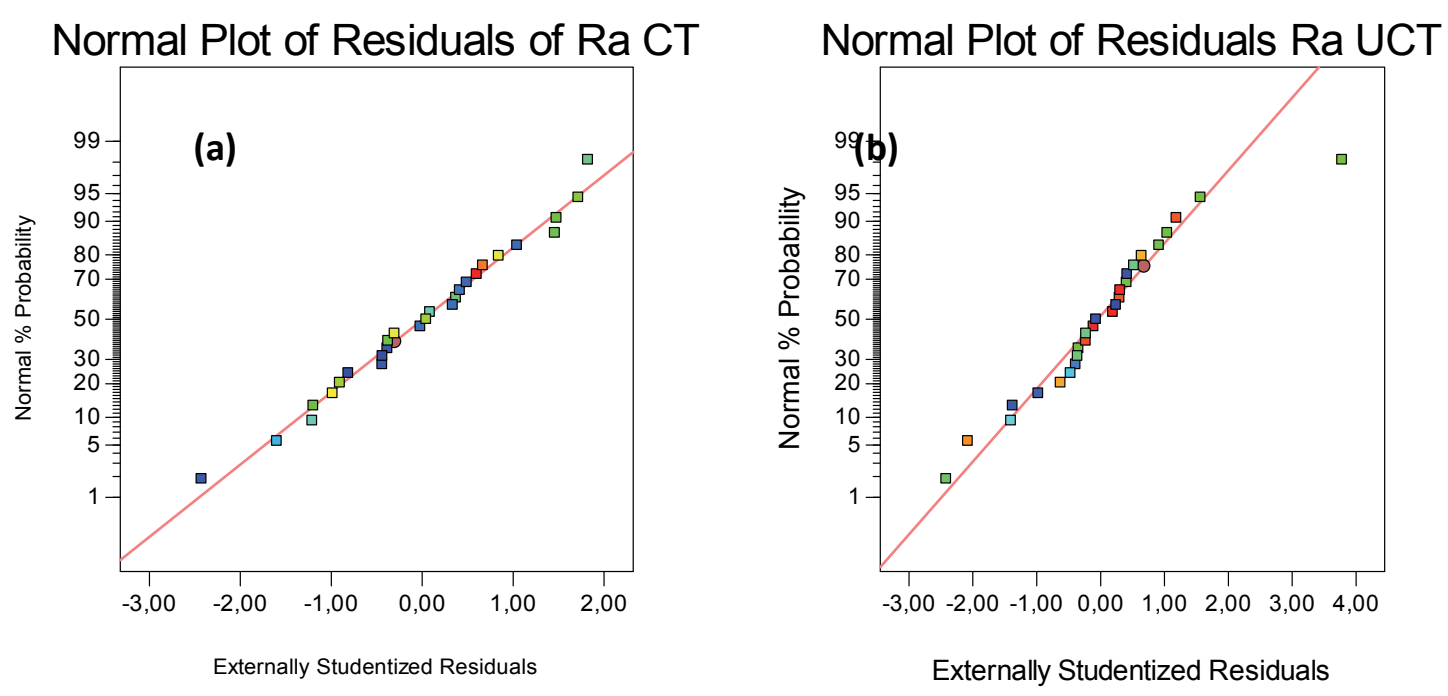

Fig. 4. Normal plot of residuals (a) for coated insert and (b) for uncoated insert

In addition, the accuracy in prediction may be found by determining the correlation coefficient (r) and root mean square of percentage deviation (e) between the theoretical and experimental values in Fig. 5 the correlation coefficient $(r)$ for " $N$ " number of observations is evaluated as

$$
r=\frac{N \sum X_{i} Y_{i}-\left(\sum X_{i}\right)\left(\sum Y_{i}\right)}{\sqrt{N \sum X_{i}^{2}-\left(\sum X_{i}\right)^{2}} \sqrt{N \sum Y_{i}^{2}-\left(\sum Y_{i}\right)^{2}}}
$$

The percentage deviation $\left(\mathrm{e}_{\mathrm{i}}\right)$ is expressed as

$$
\mathrm{e}_{\mathrm{i}}=\frac{\mathrm{X}_{\mathrm{i}}-\mathrm{Y}_{\mathrm{i}}}{\mathrm{X}_{\mathrm{i}}} \times 100
$$

Also, the root mean square of percentage deviation (e) is expressed as

$$
\mathrm{e}=\sqrt{\frac{\sum\left(\mathrm{e}_{\mathrm{i}}\right)^{2}}{\mathrm{~N}}}
$$

The coefficient of correlation value (r) for all models is 0.97 , showing a good agreement between the experimental and theoretical results. For the surface roughness with and without coating inserts, the root mean square is $2.06 \%$ and $2 \%$, respectively.

\section{4. $3 D$ surface plots}

Figs. 5 (a) and (b) shows the effect of cutting speed (Vc) and feed rate (f) on the surface roughness parameters $(\mathrm{Ra})$ with and without coating cutting tool, whereas the depth of cut (d) is kept at the middle level. In each graph of the $3 \mathrm{D}$ response surface, the four vertices represent the four combinations of the two considered factors. It is clearly observed that the feed rate $(f)$ affects strongly the surface roughness parameters. Feed rate $(f)$ has an increasing effect while the cutting speed has an important and decreasing effect. Indeed, the Surface roughness is improved by increasing the cutting speed, producing a better surface finish at higher cutting speed is a well known phenomenon in metal cutting; the conventional 
explanations are related to the built-up-edge (BUE) yallese et al. (2009). That is to say, the formation of BUE is favoured in a certain cutting speed range. By increasing cutting speed beyond this region, BUE is eliminated and as a result, the surface quality is improved. Also, Fig. 6 (a) and (b) shows the impact of the feed rate and depth of cut on the surface roughness parameter Ra using coated and uncoated insert, the analysis of this plot shows that the variation of surface roughness parameter $R a$ is proportional to the feed rate and depth of cut. These 3D illustrations clearly confirm the effects of interactions that were presented with the interaction diagrams.

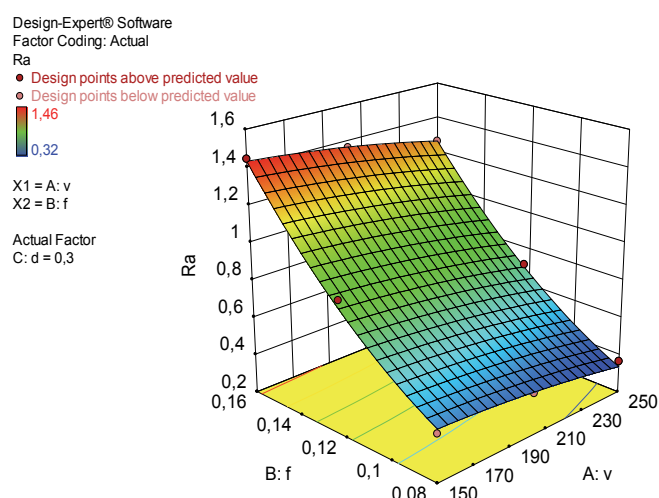

(a)

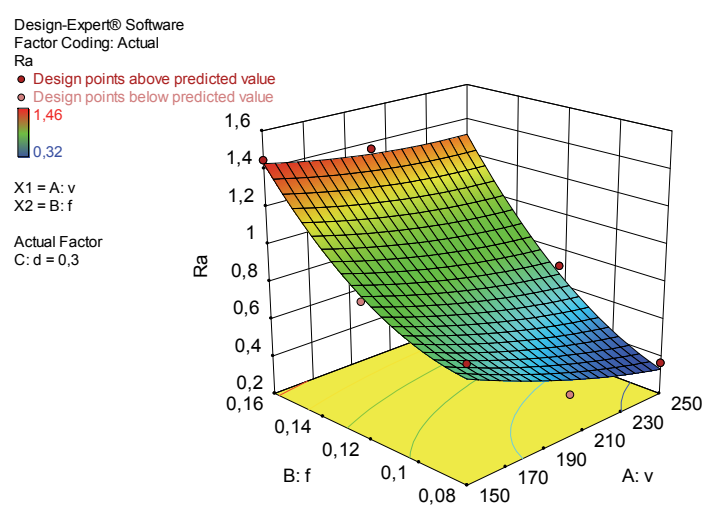

(b)

Fig. 5. Effect of cutting speed and feed rate on surface roughness Ra (a) Of coated tool and (b) Of uncoated tool

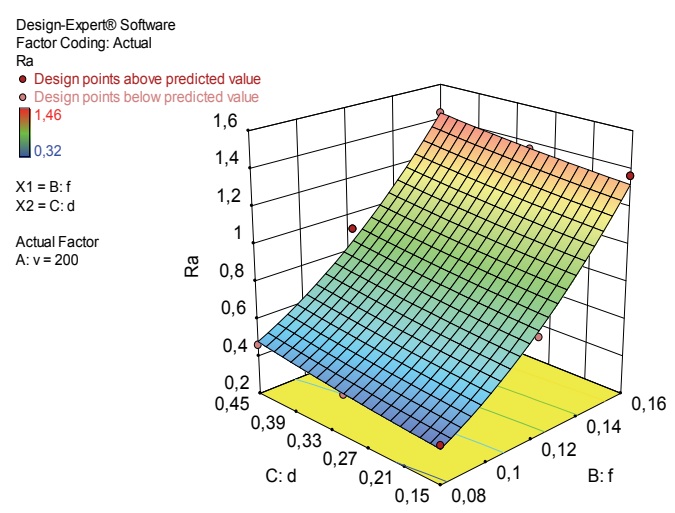

(a)

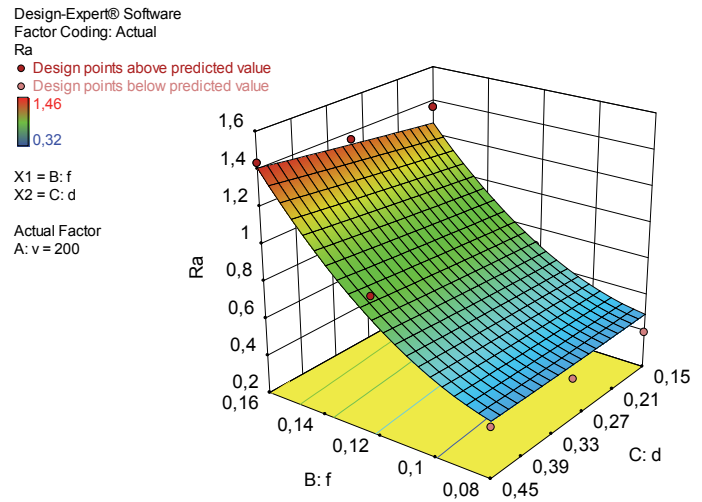

(b)

Fig. 6. Effect of feed rate and depth of cut on surface roughness Ra

(a) Of coated tool and (b) of uncoated tool

\subsection{Optimization of response}

The aim of the present experimental study is to perform a Multi-objective optimization intended for minimize roughness $\mathrm{Ra}$ and maximize material removal rate by desirability approach, using Design Expert Software. During the optimization process the aim was to find the optimal values of machining parameters in order to produce the lowest surface roughness $(\mathrm{Ra})$ with maximum material removal rate. To resolve this type of parameter design problem, an objective function, $\mathrm{F}(\mathrm{x})$, is defined as follows Myers and Montgomery, (2002).

$$
\left\{\begin{array}{c}
D F=\left(\prod_{i=1}^{n} d_{i}^{w i}\right)^{\frac{1}{\sum_{j-1}^{n} w i}} \\
F(X)=-D F
\end{array}\right.
$$


where $d_{i}$ is the desirability defined for the $\left(i^{\text {th }}\right)$ targeted output and $\mathrm{w}_{\mathrm{i}}$ is the weighting of $\mathrm{d}_{\mathrm{i}}$. For various goals of each targeted output, the desirability, $d_{i}$, is defined in different forms. If a goal is to reach a specific value of $T_{i}$, the desirability $d_{i}$ is:

$$
\begin{aligned}
& \mathrm{d}_{\mathrm{i}}=0 \quad \text { if } \mathrm{Y}_{\mathrm{i}} \leq \operatorname{Low}_{i} \\
& d_{i}=\left[\frac{Y_{i}-\text { Low }_{i}}{T_{i}-\text { Low }_{i}}\right] \text { if } \quad \operatorname{Low}_{\mathrm{i}} \leq \mathrm{Y}_{\mathrm{i}} \leq \mathrm{T}_{\mathrm{i}} \\
& d_{i}=\left[\frac{Y_{i}-H_{i g h}}{T_{i}-H_{i g h}}\right] \text { if } \mathrm{T}_{\mathrm{i}} \leq \mathrm{Y}_{\mathrm{i}} \leq \operatorname{High}_{\mathrm{i}} \\
& \mathrm{d}_{\mathrm{i}}=0 \quad \text { if } \mathrm{Y}_{\mathrm{i}} \geq \operatorname{High}_{i}
\end{aligned}
$$

For a goal to find a maximum, the desirability is shown as follows:

$$
\begin{aligned}
& \mathrm{d}_{\mathrm{i}}=0 \quad \text { if } \mathrm{Y}_{\mathrm{i}} \leq \text { Low }_{i} \\
& d_{i}=\left[\frac{Y_{i}-\text { Low }_{i}}{\text { High }_{i}-\text { Low }_{i}}\right] \text { if } \quad \operatorname{Low}_{\mathrm{i}} \leq \mathrm{Y}_{\mathrm{i}} \leq \operatorname{High}_{\mathrm{i}} \\
& \mathrm{d}_{\mathrm{i}}=1 \quad \text { if } \mathrm{Y}_{\mathrm{i}} \geq \operatorname{High}_{i}
\end{aligned}
$$

For a goal to search for a minimum, the desirability can be defined by the following formulas:

$$
\begin{aligned}
& \mathrm{d}_{\mathrm{i}}=1 \quad \text { if } \mathrm{Y}_{\mathrm{i}} \leq \operatorname{Low}_{i} \\
& d_{i}=\left[\frac{\operatorname{High}_{i}-Y_{i}}{\operatorname{High}_{i}-\operatorname{Low}_{i}}\right] \text { if } \operatorname{Low}_{\mathrm{i}} \leq \mathrm{Y}_{\mathrm{i}} \leq \operatorname{High}_{\mathrm{i}} \\
& \mathrm{d}_{\mathrm{i}}=0 \quad \text { if } \mathrm{Y}_{\mathrm{i}} \geq \operatorname{High}_{i}
\end{aligned}
$$

where, $Y_{i}$ is the found value of the $\left(i^{\text {th }}\right)$ output during optimization processes. Low $\mathrm{w}_{i}$ and High $\mathrm{H}_{\mathrm{i}}$ are respectively, the minimum and the maximum values of the experimental data for the $\left(i^{\text {th }}\right)$ output. In Eq. (8), $\mathrm{w}_{\mathrm{i}}$ is set to one since the $\mathrm{d}_{\mathrm{i}}$ is important in this study. DF is a combined desirability function Myers \& Montgomery, (2002), and the objective is to choose an optimal setting that maximizes a combined Desirability Function (DF) minimizes $\mathrm{F}(\mathrm{x})$. Table7 shows the goals, parameter ranges and importance degrees for the output parameters. The optimum cutting parameters obtained for $R a$ and $M R R$ using coated cermet are chosen in terms of the highest desirability value with cutting speed (v) of $250 \mathrm{~m} / \mathrm{mn}$, feed rate (f) of $0.113 \mathrm{~mm} / \mathrm{rev}$ and depth of cut (d) of $0.45 \mathrm{~mm}$, where the optimal solutions are reported in Table 8 in order to decrease the desirability level. On the other hand, for uncoated cermet, the optimal cutting parameters are cutting speed (v) of $250 \mathrm{~m} / \mathrm{mn}$, feed rate (f) of $0.102 \mathrm{~mm} / \mathrm{rev}$ and depth of cut (d) of $0.45 \mathrm{~mm}$, as indicated in Table 8 . The predicted responses of coated insert are $\mathrm{Ra}=0.63 \mu \mathrm{m}$ and 12.75 $\mathrm{cm}^{3} / \mathrm{min}$ for MRR, with desirability value of 0.72 , by against to uncoated insert the values of predicted responses are $\mathrm{Ra}=0.54 \mu \mathrm{m}$ and $11.629 \mathrm{~cm}^{3} / \mathrm{min}$ for MRR, with desirability value of 0.698 . The Fig. (79) presents the contour plot for Desirability of multi-objective optimization, the contour plot for surface roughness ( $\mathrm{Ra}$ ) and the contour plot for productivity (MRR) using coated insert, in relation to the cutting speed (Vc) feed rate (f) and depth of cut (d). For each plot, the variables not represented are held at the optimal value. Besides, the estimated contour plot using uncoated tool are depicted in Fig.(10-12) as a function of cutting speed, feed rate and depth of cut. 
Table 7

Constraints for optimization of machining parameters

\begin{tabular}{lcccccc}
\hline Name & Goal & Lower Limit & Upper Limit & Lower Weight & Upper Weight & Importance \\
\hline $\mathrm{V}(\mathrm{m} / \mathrm{mn})$ & in range & 120 & 250 & 1 & 1 & 1 \\
$\mathrm{f}(\mathrm{mm} / \mathrm{rev})$ & in range & 0,08 & 0,16 & 1 & 1 & 3 \\
$\mathrm{~d}(\mathrm{~mm})$ & in range & 0,15 & 0,45 & 1 & 1 & 3 \\
Ra coated tool $(\mu \mathrm{m})$ & minimize & 0.39 & 1.42 & 1 & 1 & 3 \\
Ra uncoated tool $(\mu \mathrm{m})$ & minimize & 0,32 & 1,46 & 1 & 1 & 3 \\
$\mathrm{Q}$ coated tool $\left(\mathrm{cm}^{3} / \mathrm{min}\right)$ & maximize & 1.8 & 18 & & & 3 \\
\hline
\end{tabular}

\section{Table 8}

Optimal solutions

\begin{tabular}{clccccccc}
\hline Number & Cutting tool & $\mathrm{v}$ & $\mathrm{f}$ & $\mathrm{d}$ & $\mathrm{Ra}$ & $\mathrm{Q}$ & Desirability & remarks \\
\hline \multirow{2}{*}{1} & Coated tool & 250 & 0.113 & 0.45 & 0.631 & 12.75 & 0.720 & suggested \\
& Uncoated tool & 250 & 0.102 & 0.45 & 0.545 & 11.629 & 0.698 & suggested \\
\hline \multirow{2}{*}{2} & Coated tool & 250 & 0.113 & 0.45 & 0.634 & 12.75 & 0.720 & - \\
& Uncoated tool & 250 & 0.102 & 0.45 & 0.542 & 11.602 & 0.698 & - \\
\hline \multirow{2}{*}{3} & Coated tool & 250 & 0.113 & 0.45 & 0.628 & 12.75 & 0.720 & - \\
& Uncoated tool & 250 & 0.102 & 0.45 & 0.549 & 11.673 & 0.698 & - \\
\hline
\end{tabular}

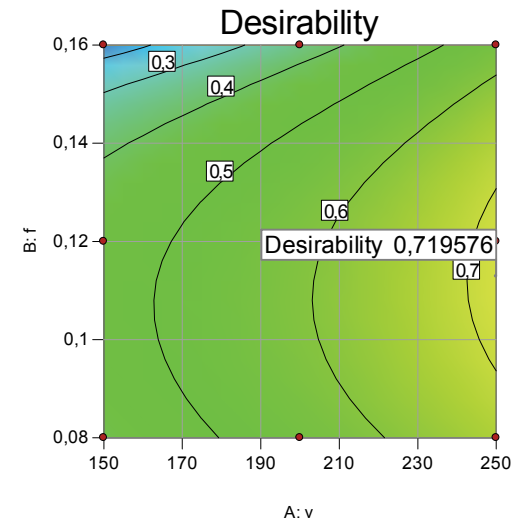

(a)

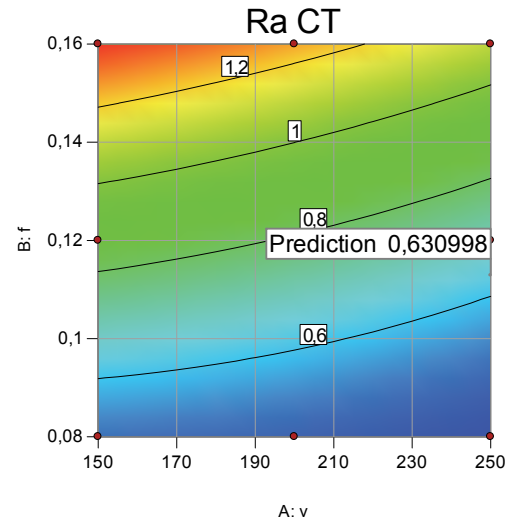

(b)

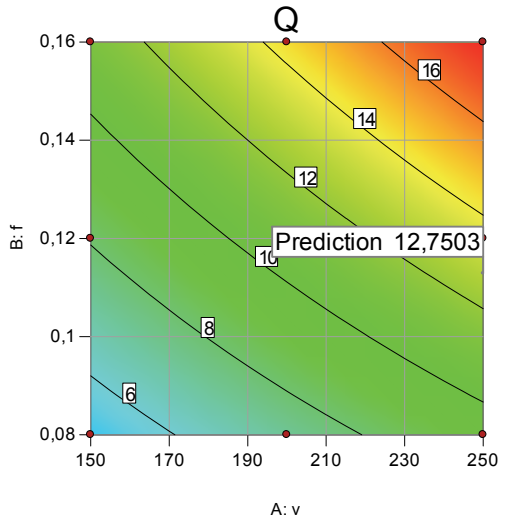

(c)

Fig.7. (a) Contour plot for Desirability of multi-objective optimization

(b) Contour plot for Ra of coated tool, (c) Contour plot for MRR of coated tool,

While (d) kept at the optimal value

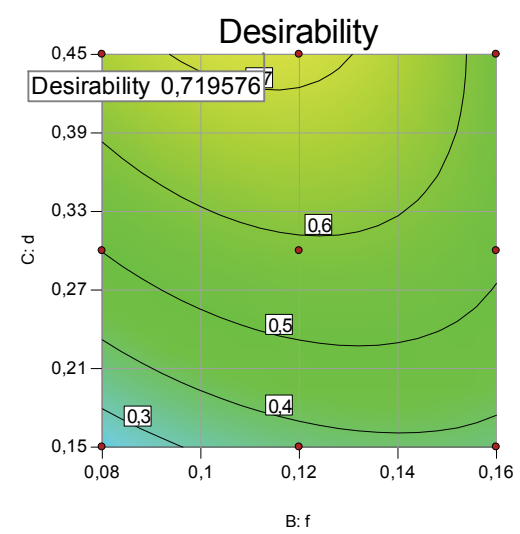

(a)

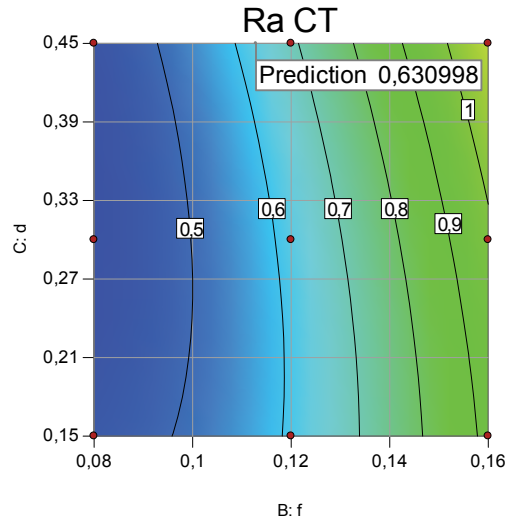

(b)



(c)

Fig.8. (a) Contour plot for Desirability of multi-objective optimization

(b) Contour plot for Ra of coated tool, (c) Contour plot for MRR of coated tool while (V) kept at the optimal value 


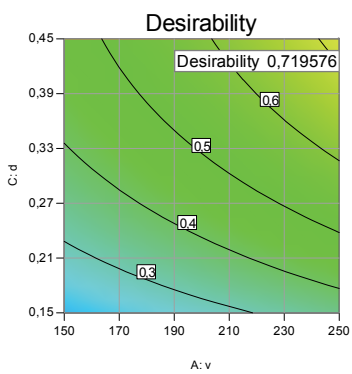

(a)

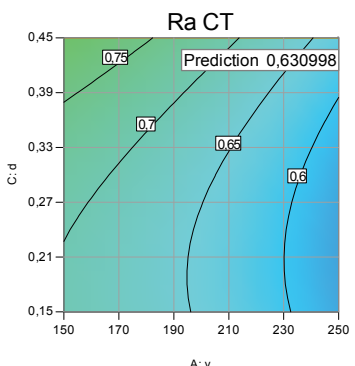

(b)

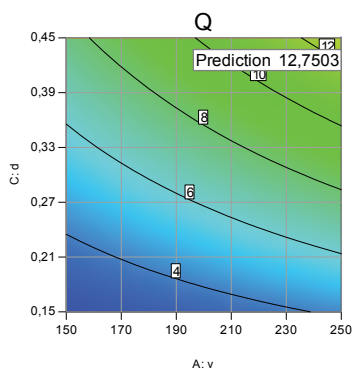

(c)

Fig. 9. (a) Contour plot for Desirability of multi-objective optimization

(b) Contour plot for Ra of coated tool, (c) Contour plot for MRR of coated tool, while (f) kept at the optimal value

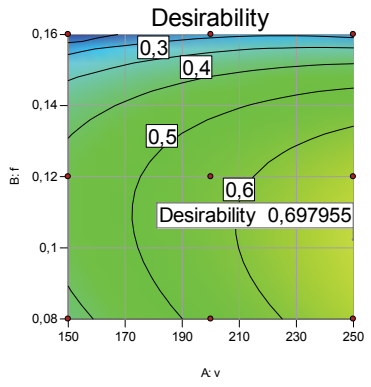

(a)

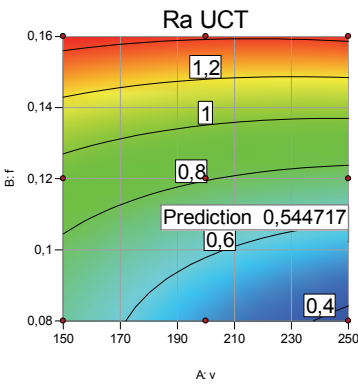

(b)

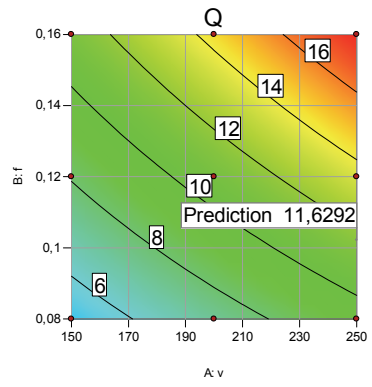

(c)

Fig.10. (a) Contour plot for Desirability of multi-objective optimization

(b) Contour plot for Ra of uncoated tool, (c) Contour plot for MRR of uncoated tool, while (d) kept at the optimal value

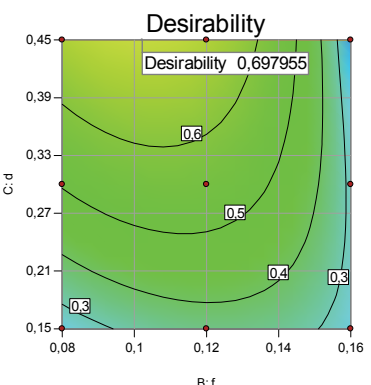

(a)

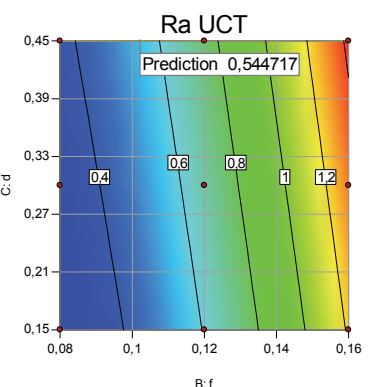

(b)

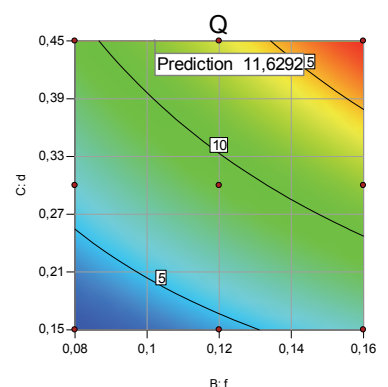

(c)

Fig. 11. (a) Contour plot for Desirability of multi-objective optimization

(b) Contour plot for Ra of uncoated tool, (c) Contour plot for MRR of uncoated tool while (V) kept at the optimal value

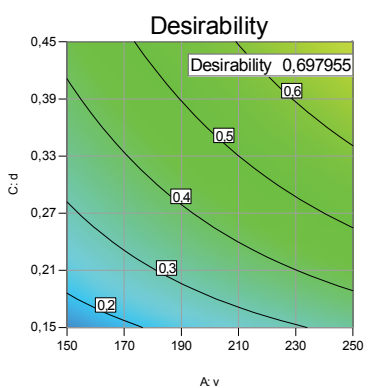

(a)

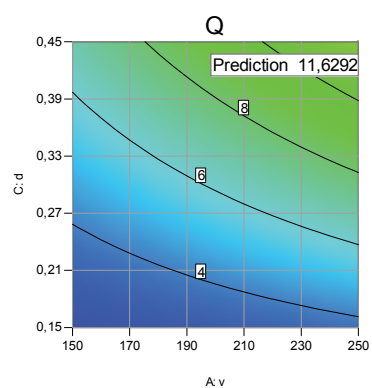

(c)

Fig. 12. (a) Contour plot for Desirability of multi-objective optimization

(b) Contour plot for Ra of uncoated tool, (c) Contour plot for MRR of uncoated tool while (f) kept at the optimal value 


\section{Conclusions}

In this work, the impact of coating material of cutting tool and cutting parameters on surface roughness are analyzed and optimized, in dry turning of AISI 52100 steel. The important findings are recapitulated as follows:

1) ANOVA result using coated cermet of surface roughness shows that feed rate is the most significant parameter that contributes toward the output responses by $93.95 \%$. The effect of cutting speed is only $2.32 \%$, followed by depth of cut by $1.27 \%$, which are negligible. Versus, to uncoated insert the effect of feed rate is the most significant parameter with the percent contribution of $82.09 \%$. The effect of cutting speed is only of $7.41 \%$, followed by depth of cut by $0.51 \%$.

2) High surface quality are obtained when employing PVD (TiCN-TiN) coated insert. The coating effect on the surface roughness is improved from 0.77 for the uncoated insert to 0.89 for the coated one.

3) The coefficient of correlation ( $r$ ) was of 0.97 and the root mean square of percent deviation values varies in the range of $2.64 \%$ to $2 \%$. Consequently, a good agreement was found between the proposed theoretical models and the experimental data.

4) Desirability of multi-objective optimization results using coated insert shows that the optimum cutting parameters obtained, are cutting speed (v) of $250 \mathrm{~m} / \mathrm{mn}$, feed rate (f) of $0.113 \mathrm{~mm} / \mathrm{rev}$ and depth of cut (d) of $0.45 \mathrm{~mm}$, which are chosen in terms of the highest desirability value with 0.72 , which gives the predicted responses are $\mathrm{Ra}=0.63 \mu \mathrm{m}$, and $12.75 \mathrm{~cm} 3 / \mathrm{min}$ for MRR.

5) Furthermore, for uncoated cermet, the optimal cutting parameters are cutting speed (v) of $250 \mathrm{~m} / \mathrm{mn}$, feed rate (f) of $0.102 \mathrm{~mm} / \mathrm{rev}$ and depth of cut (d) of $0.45 \mathrm{~mm}$. The values of predicted responses are $\mathrm{Ra}=0.54 \mu \mathrm{m}$, and $11.629 \mathrm{~cm} 3 / \mathrm{min}$ for MRR, with desirability value of 0.698 , In this study, the using optimization methodology is a powerful approach and can present to scientific works as well machining process a helpful optimization procedure.

\section{Acknowledgements}

This work was achieved in the (LRTAPM) Advanced Technologies in Mechanical Production Research Laboratory (University of Annaba, Algeria) in collaboration with the laboratories LMS (University of Guelma Algeria). The authors would like to thank the Algerian Ministry of Higher Education and Scientific Research (MESRS) and the Delegated Ministry for Scientific Research (MDRS) for granting financial support for CNEPRU Research Project (University of Annaba, Algeria).

\section{References}

Aouici, H., Fnides, B., Elbah, M., Benlahmidi, S., Bensouilah, H., \& Yallese, M. A. (2016). Surface roughness evaluation of various cutting materials in hard turning of AISI H11. International Journal of Industrial Engineering Computations, 7(2), 339.

Asiltürk, I., \& Akkuş, H. (2011). Determining the effect of cutting parameters on surface roughness in hard turning using the Taguchi method. Measurement,44(9), 1697-1704.

Aurich, J. C., Eyrisch, T., \& Zimmermann, M. (2012). Effect of the coating system on the tool performance when turning heat treated AISI 4140. Procedia CIRP, 1, 214-219.

Azizi, M. W., Belhadi, S., Yallese, M. A., Mabrouki, T., \& Rigal, J. F. (2012). Surface roughness and cutting forces modeling for optimization of machining condition in finish hard turning of AISI 52100 steel. Journal of Mechanical Science and Technology, 26(12), 4105-4114.

Berkani, S., Yallese, M., Boulanouar, L., \& Mabrouki, T. (2015). Statistical analysis of AISI304 austenitic stainless steel machining using $\mathrm{Ti}(\mathrm{C}, \mathrm{N}) / \mathrm{Al} 2 \mathrm{O} 3 / \mathrm{TiN}$ CVD coated carbide tool. International Journal of Industrial Engineering Computations, 6(4), 539-552. 
Bouchelaghem, H., Yallese, M. A., Amirat, A., \& Belhadi, S. (2007). Wear behaviour of CBN tool when turning hardened AISI D3 steel. Mechanika, 65(3), 57-65.

Bouzid, L., Boutabba, S., Yallese, M. A., Belhadi, S., \& Girardin, F. (2014). Simultaneous optimization of surface roughness and material removal rate for turning of $\mathrm{X} 20 \mathrm{Cr} 13$ stainless steel. The International Journal of Advanced Manufacturing Technology, 74(5-8), 879-891.

Cakir, M. C., Ensarioglu, C., \& Demirayak, I. (2009). Mathematical modeling of surface roughness for evaluating the effects of cutting parameters and coating material. Journal of Materials Processing Technology, 209(1), 102-109.

Chinchanikar, S., \& Choudhury, S. K. (2013). Effect of work material hardness and cutting parameters on performance of coated carbide tool when turning hardened steel: An optimization approach. Measurement, 46(4), 1572-1584.

Das, S. R., Dhupal, D., \& Kumar, A. (2015). Experimental investigation into machinability of hardened AISI 4140 steel using TiN coated ceramic tool.Measurement, 62, 108-126.

Elbah, M., Yallese, M. A., Aouici, H., Mabrouki, T., \& Rigal, J. F. (2013). Comparative assessment of wiper and conventional ceramic tools on surface roughness in hard turning AISI 4140 steel. Measurement, 46(9), 3041-3056.

Grzesik, W. (1998). The role of coatings in controlling the cutting process when turning with coated indexable inserts. Journal of Materials Processing Technology, 79(1), 133-143.

Grzesik, W., \& Nieslony, P. (2004). Prediction of friction and heat flow in machining incorporating thermophysical properties of the coating-chip interface.Wear, 256(1), 108-117.

Hessainia, Z., Belbah, A., Yallese, M. A., Mabrouki, T., \& Rigal, J. F. (2013). On the prediction of surface roughness in the hard turning based on cutting parameters and tool vibrations. Measurement, 46(5), 1671-1681.

Lin, T. R. (2002). Experimental design and performance analysis of TiN-coated carbide tool in face milling stainless steel. Journal of Materials Processing Technology, 127(1), 1-7.

Myers, R.H., \& Montgomery, D.C. (2002). Response surface methodology: process and product optimization using designed experiments. $2^{\text {nd }}$ ed. John Wiley and Sons, Inc.: New York,

Sahoo, A. K., \& Sahoo, B. (2012). Experimental investigations on machinability aspects in finish hard turning of AISI 4340 steel using uncoated and multilayer coated carbide inserts. Measurement, 45(8), 2153-2165.

Sahoo, A. K., \& Sahoo, B. (2013). Performance studies of multilayer hard surface coatings (TiN/TiCN/Al $2 \mathrm{O} 3 / \mathrm{TiN}$ ) of indexable carbide inserts in hard machining: Part-I (An experimental approach). Measurement, 46(8), 2854-2867.

Tebassi, H., Yallese, M., Khettabi, R., Belhadi, S., Meddour, I., \& Girardin, F. (2016). Multi-objective optimization of surface roughness, cutting forces, productivity and Power consumption when turning of Inconel 718. International Journal of Industrial Engineering Computations, 7(1), 111-134.

Yallese, M. A., Chaoui, K., Zeghib, N., Boulanouar, L., \& Rigal, J. F. (2009). Hard machining of hardened bearing steel using cubic boron nitride tool. Journal of Materials Processing Technology, 209(2), 1092-1104.

Zahia, H., Athmane, Y., Lakhdar, B., \& Tarek, M. (2015). On the application of response surface methodology for predicting and optimizing surface roughness and cutting forces in hard turning by PVD coated insert. International Journal of Industrial Engineering Computations, 6(2), 267-284.

Zhang, K., Deng, J., Meng, R., Gao, P., \& Yue, H. (2015). Effect of nano-scale textures on cutting performance of WC/Co-based Ti $55 \mathrm{Al} 45 \mathrm{~N}$ coated tools in dry cutting. International Journal of Refractory Metals and Hard Materials, 51, 35-49.

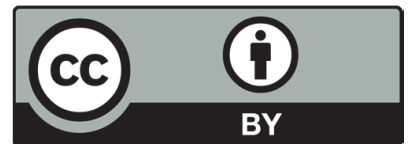

(C) 2016 by the authors; licensee Growing Science, Canada. This is an open access article distributed under the terms and conditions of the Creative Commons Attribution (CCBY) license (http://creativecommons.org/licenses/by/4.0/). 